\title{
Dos visiones de la Unión Soviética: Stefan Zweig y Manuel Chaves Nogales
}

\author{
Stefan Zweig and Manuel Chaves Nogales: \\ Two looks about USRR
}

\author{
JaVier SÁNChez Zapatero \\ Universidad de Salamanca. Salamanca, España \\ zapa@usal.es
}

\section{RESUMEN}

El impacto de la Revolución Rusa sobre la sociedad occidental motivó que intelectuales de todo el mundo se desplazaran a la URSS para presenciar los cambios efectuados en la sociedad soviética, escribiendo sobre su viaje en diversas obras. El artículo analiza los testimonios de Stefan Zweig y Manuel Chaves Nogales, quienes viajaron a la URSS en 1928, e incide en la visión imparcial e independiente que ambos proyectan sobre el proceso revolucionario, muy diferente al dogmatismo de la época.

Palabras clave: Libros de viajes, literatura comparada.

\section{ABSTRACT}

The impact of the Russian Revolution caused that many intellectuals traveled to USSR in 1920's and 1930's in order to know the revolution process and to write about it. This paper analyzes the testimony of the trips of Stefan Zweig and Manuel Chaves Nogales. Both writers went to the USSR in 1928 and they offered in their works an impartial and independent interpretation -without dogmatism- about the Revolution and the life in USSR.

Keywords: Travel literature, comparative literature.

Recibido: 03.07.2012. Aceptado: 18.02.2013. 


\section{EL VIAJE Y EL RELATO}

Ctefan Zweig y Manuel Chaves Nogales viajaron por primera vez a la $\checkmark$ Unión Soviética en la segunda mitad del año 1928. Mientras que el primero fue invitado, como delegado de los escritores austriacos, a participar en las celebraciones del centenario del nacimiento de Tolstoi -que se conmemoraba el 9 de septiembre en Yásnaia Poliana, la finca rural de Tula en la que vivió y fue enterrado el autor ruso-, el segundo hizo escala en diversas ciudades del país dentro del viaje en avión que lo llevó a recorrer buena parte de Europa con el fin de escribir un reportaje para el Heraldo de Madrid, diario del que era por aquel entonces redactor jefe.

El escritor austriaco dedicó unas páginas a su periplo en la Unión Soviética en diversos artículos que se publicaron en el periódico vienés Neue Freie Presse a finales de octubre y comienzos de noviembre de 1928 y, años más tarde, en El mundo de ayer. Memorias de un europeo (Sternstunden der Menschheit, 1942), el libro póstumo de memorias que daba cuenta de las transformaciones sufridas por el continente europeo en la convulsa primera mitad del siglo XX. Zweig, testigo de excepción de esos cambios en su doble condición de escritor de éxito y viajero impenitente ${ }^{1}$, relató en su autobiografía de qué forma los sólidos basamentos que parecían sostener a la sociedad occidental se vinieron abajo en unos años marcados por la ferocidad de las dos guerras mundiales, el odio cainita entre los países europeos, los grandes fenómenos exílicos y, sobre todo, el nacimiento y expansión de "las grandes ideologías de masas: el fascismo en Italia, el nacionalsocialismo en Alemania y el bolchevismo en Rusia" (Zweig, 2002: 13). El autor permaneció tan solo quince días en la Unión Soviética, donde gozaba de cierto predicamento gracias al éxito de sus libros y a la admiración que por sus obras sentía Máximo Gorki², prologuista de alguna de sus ediciones rusas. Viajó en tren desde Austria, recorriendo la recién creada Segunda República de Polonia, y pasó entre Leningrado, Tula y, sobre todo, Moscú las dos semanas que permaneció en territorio ruso.

Chaves Nogales, por su parte, salió de Madrid el 6 de agosto, iniciando

${ }^{1}$ De su afición por los viajes dan testimonio las palabras que Romain Rolland escribió en el prólogo de la edición francesa de Amok (Der Amokläufer, 1922): "Zweig siempre está de viaje, roza todos los territorios de la cultura, siempre observando y anotando, sus obras más personales las escribe durante fugaces paradas en alguna habitación de hotel" (Matuschek, 2009: 244).

${ }^{2}$ Zweig y Gorki se conocieron personalmente durante la estancia del austriaco en Moscú y dos años después volvieron a coincidir en Italia. Entre ellos se estableció una cordial -y singular- relación de complicidad, tal y como manifestó el propio Zweig: "Nos llevamos de maravilla a pesar de que ninguno de los dos entiende la lengua del otro" (Matuschek, 2009: 247). 
así un periplo de más de 16.000 kilómetros -todo un hito para la incipiente industria aeronáutica de la época, y también para el periodismo español, al que situó "a la vanguardia del riesgo informativo" (Cintas Guillén, 2001: 44) con semejante empresa ${ }^{3}$ - que le llevó a recorrer capitales europeas como Roma, París, Bruselas, Berlín, Viena, Varsovia o, claro está, Moscú, y que finalizó en el mes de noviembre. Durante los cuatro meses del viaje fue enviando puntualmente reportajes a su periódico en los que describía la geografía humana y espacial de los diferentes lugares que fue visitando. Un año después de su publicación en el diario, el autor decidió recopilar todo ese material y, convenientemente ampliado, editarlo en forma de libro ${ }^{4}$. Nació así La vuelta al mundo en avión. Un pequeño burgués en la Rusia roja (1929) que, más que una mera compilación de reportajes o un libro de viajes, puede ser considerado, además del relato de la aventura que suponía recorrer el continente volando en $1928^{5}$, como un "análisis de la situación ideológica de Europa, algo así como un mapa espiritual” (Cintas Guillén, 2001: 44) en el que el autor abordaba con especial insistencia dos temas que, a la postre, serían cruciales en el desarrollo histórico y político del continente: el crecimiento de los fascismos y las consecuencias de la Revolución Rusa. De ahí que, a pesar de ser solo uno más de los destinos de viaje, la Unión Soviética se convirtiera en tema central del libro, como prueban su subtítulo, la gran cantidad de páginas que el autor dedicó a ofrecer sus reflexiones sobre ciudades como Moscú, Leningrado, Danzig o Bakú, o el hecho de que la editorial Mundo Latino, responsable de la primera edición, incluyese en la información paratextual del libro que se trataba de uno de los "más completos, veraces y agudos sobre la vida en el régimen bolchevique".

El interés por la cultura rusa en general, y por lo acontecido tras la revolución en particular, estuvo presente de forma constante en la producción literaria de los dos autores. Zweig escribió sendos ensayos sobre Dostoievski

\footnotetext{
${ }^{3}$ Reportajes como el de Chaves Nogales fueron habituales en el periodismo español de la década de 1920, tal y como evidencia, por ejemplo, el caso de Luis de Oteyza -autor de la serie "Al Senegal en avión", publicada también en Heraldo de Madrid en 1927 y 1928, y De España al Japón (1927), libro que recogía sus más destacados artículos sobre sus viajes al extranjero-. Según María Isabel Cintas Guillén (2001: 42-46), para entender la fiebre por este tipo de reportajes hay que hacer referencia tanto a que "la aviación se convierte en uno de los focos de mayor atracción para el hombre de principios del siglo XX" como a que "el público lector exigía emoción, [obligando] al periodista a abandonar la comodidad de la redacción".

${ }^{4}$ Para analizar las semejanzas y diferencias entre lo publicado en el periódico y lo incluido en el libro, véase el estudio de Cintas Guillén (2001: 48-56).

${ }^{5}$ Del carácter aventurero de la peripecia dan fe el aterrizaje forzoso que el avión hubo de hacer cerca de la localidad francesa de Bézieres, o los varios días que Chaves permaneció, tras un accidente, deambulando totalmente perdido por la cordillera caucásica.
} 
y Tolstoi -incluidos, respectivamente, en sus obras Tres maestros: Balzac, Dickens, Dostoievski (Drei Meister: Balzac, Dickens, Dostoievski, 1920) y Tres poetas de su vida: Casanova, Stendhal, Tolstoi (Drei Dichter ihres Lebens: Casanova, Stendhal, Tolstoi, 1928)-, e incluyó en Momentos estelares de la humanidad. Catorce miniaturas históricas (Sternstunden der Menschheit, 1930) los relatos del viaje de Lenin a Rusia en 1917 desde su exilio suizo, poco después del inicio de la Revolución, y del indulto a Dostoievski en 1849, momentos antes de que se ejecutara la sentencia de muerte por conspirar contra el gobierno zarista. En cuanto a Chaves Nogales, compuso los reportajes Lo que ha quedado del imperio de los zares (1931) -centrado en las condiciones de vida de los miles de rusos que se vieron obligados a exiliarse después del triunfo bolchevique- y El maestro Juan Martínez que estuvo allí (1934) -biografía de un bailaor flamenco que, de gira artística por Europa, fue testigo de excepción de los sucesos revolucionarios ${ }^{6}$-, así como la novela La bolchevique enamorada (1929).

\section{EL IMPACTO DE LA REVOLUCIÓN RUSA}

Los viajes de Zweig y Chaves Nogales, así como sus deseos de dejar constancia de ellos, evidencian el impacto que produjo en la sociedad europea la Revolución Rusa, que incrementó la curiosidad que desde tiempos inmemoriales se había tenido por el exotismo del mundo oriental ${ }^{7}$. Tal y como ha señalado María Isabel Cintas Guillén (2001: 68) aludiendo al interés que en España despertó todo lo relacionado con el régimen soviético, "el pueblo se sentía atraído por todo lo que tuviera que ver con el asunto, y el acercamiento a la cotidianeidad [sic] de los bolcheviques resultaba de un inmenso atractivo". Según Coser (1997: 241), semejante admiración puede explicarse por la promesa del comunismo de satisfacer las dos necesidades básicas del hombre de la época: la económica y la espiritual.

Los sucesos acaecidos entre 1917 y 1921, y sus consiguientes consecuencias, atrajeron la atención de la ciudanía occidental. En general, existía la

\footnotetext{
${ }^{6}$ En su análisis del texto Cintas Guillén (2001: 96) se refiere a la capacidad de Chaves Nogales para adaptarse a los gustos del público lector de la época, entre el que se había despertado el interés por los libros autobiográficos debido al éxito de los títulos de autores como, precisamente, Stefan Zweig.

${ }^{7}$ Para Lewis A. Coser (1997: 231-232), este interés fue especialmente perceptible en los ámbitos intelectuales a partir del siglo XVIII debido a la admiración que los filósofos ilustrados franceses sintieron por el respeto con el que la sociedad de imperios orientales como el Ruso o el Chino trataba a los hombres de letras, a quienes se veneraba y seleccionaba para importantes puestos de poder.
} 
convicción de encontrarse ante el cambio social y político más importante de la historia del mundo desde la Revolución Francesa. Así lo expresó, por ejemplo, André Malraux, quien llegó a calificar lo sucedido como una forma de "asunción del pueblo" (Tood, 2002: 200) heredera de la rebelión gala de 1789. Otros intelectuales, como el español Pedro Garfías (2001: 86) -que interpretó la toma de poder bolchevique como "la experiencia más vasta y de interés más definitivo que ha acometido nunca la humanidad"- 0 el también francés André Gide (1982: 13) -quien afirmó en 1935 que la Unión Soviética ofrecía "un espectáculo sin precedentes, de una importancia inmensa [e] inesperada"-, se manifestaron en términos parecidos a los de Malraux. No en vano, según Fulgencio Castañar (1992: 35), "la imantación que debió ejercer [la Revolución Rusa] (...) sobre los intelectuales europeos fue inmensa". Semejante atracción se constata atendiendo al ingente número de publicaciones que sobre lo acontecido en Rusia se editaron durante las décadas de 1920 y $1930^{8}$, a la difusión en Europa de la literatura de escritores rusos como Máximo Gorki o Iliá Erenburg y, sobre todo, a la gran cantidad de intelectuales que, como Zweig y Chaves Nogales, viajaron para comprobar in situ cuál era la realidad del país y cómo estaban afectando a la sociedad los cambios impuestos por el gobierno bolchevique.

Bernard Shaw, H. G. Wells, John Dos Passos, Henri Barbusse, André Gide, André Malraux, Halldor Kiljan Laxness, Panait Istrati, Max Aub, Rafael Alberti, María Teresa León, Miguel Hernández, Ramón J. Sender o Pablo Neruda fueron algunos de los escritores de la época que se desplazaron hasta la Unión Soviética, cegados en ocasiones por el brillo de la revolución y, por tanto, condicionados por la imagen mítica que les había llegado del acontecimiento'. No fue ese, sin embargo, el caso de Stefan Zweig y Manuel Chaves Nogales, quienes acudieron a la Unión Soviética llamados, más que

\footnotetext{
${ }^{8}$ Según Julián Gorkin, "quizá haya sido España el país donde se han editado más libros sobre la Revolución Rusa (...). Los jóvenes españoles, al igual que la parte más adelantada del pueblo obrero, devoraban febrilmente dicha literatura" (Caudet, 1993: 131). Así, durante los años 1919 y 1920 aparecieron en el catálogo de la editorial Biblioteca Nueva, inmersos en la colección "Las nuevas doctrinas sociales", alrededor de una veintena de libros destinados a explicar lo acontecido en Rusia, entre los que se encontraban varias de las obras escritas por Lenin -El Estado y la revolución proletaria, Ideario bolchevista, El comunismo de izquierda, el capitalismo de Estado y el impuesto en especie y La victoria proletaria y el renegado Kausky-. Además, los sucesos de Rusia se convirtieron en fuente de inspiración literaria, pues "la Revolución (...) y los revolucionarios como agentes propulsores fueron temas que aparecieron en las novelas desde perspectivas distintas" (Castañar, 1992: 159), como demuestran las obras de, por ejemplo, Joaquín Arderíus o José María Carretero.

${ }^{9}$ Para profundizar en la atracción que la Revolución Rusa produjo en la intelectualidad occidental, consúltese el capítulo "Salvation Abroad" del libro Men of Ideas. A Sociologist's View de Lewis A. Coser (1997: 227-241).
} 
por la admiración hacia el halo utópico que rodeaba a todo lo sucedido tras la revolución, por la curiosidad ${ }^{10}$.

El talante independiente y crítico de ambos autores, contrario a cualquier dogmatismo partidista, subyace a su mirada sobre la sociedad rusa y dota a sus obras de una objetividad que contrasta con la de la mayoría de los intelectuales que por aquellas fechas viajaron a la Unión Soviética. El propio Zweig fue consciente de ello, al afirmar que a pesar de su "ardiente curiosidad" y de que "Rusia se había convertido (...) en el país más fascinante de la posguerra", no se decidió a viajar hasta recibir la invitación para acudir a los fastos del homenaje a Tolstoi por miedo a ser encasillado políticamente:

Me retenía el hecho de que viajar a Rusia en aquellos momentos significaba en cierto modo ya a priori tomar partido, cosa que me obligaba a pronunciarme en uno de los dos sentidos: reconocimiento o rechazo. (...) [Pero] no tenía ningún motivo para declinar la invitación puesto que mi visita, exenta de todo partidismo, eludía cualquier aspecto político (Zweig, 2002: 413-414).

De hecho, ni las páginas de El mundo de ayer. Memorias de un europeo dedicadas a la estancia de Zweig en la Unión Soviética ni los reportajes de Chaves Nogales encajan en ninguno de los grandes grupos en los que pueden dividirse los libros de viajes en los que se reflexionó sobre el impacto de la revolución, que, grosso modo, oscilaron entre el tono laudatorio de quienes alabaron al régimen bolchevique y su esfuerzo por crear una sociedad justa, igualitaria y humanitaria, y el carácter desengañado de aquellos que, lejos de ver en el modelo soviético rastro alguno de ejemplaridad, viraron ideológicamente tras entrar en contacto con las condiciones reales de vida del país y conocer la pobreza, la falta de libertad o la represión ${ }^{11}$. Al primero de los grupos pertenecerían, por ejemplo, las páginas que Alberti o Neruda dedicaron a su estancia en la Unión Soviética en sus autobiografías La arbo-

${ }^{10} \mathrm{La}$ misma actitud aséptica e inquieta de Zweig y Chaves mantuvieron en su viaje autores como Max Aub o John Dos Passos, más interesados en conocer cuestiones puntuales sobre la cultura y la cotidianidad soviéticas que en reflexionar sobre el impacto de la Revolución. El escritor español acudió a la URSS enviado por el periódico madrileño Luz para elaborar una serie de artículos sobre la situación del teatro en el país, mientras que el autor norteamericano reconoció viajar para poder estudiar las características de las artes escénicas soviéticas y "de paso (...) saber cómo vivía la gente en un régimen socialista" (Dos Passos, 1984: 212).

${ }^{11}$ Para profundizar en los testimonios de quienes se desplazaron a Rusia en esta época, consúltese el artículo "Utopía y desengaño: análisis comparatista de los libros de viajes a la URSS" (Sánchez Zapatero, 2008). 
leda perdida (1942) y Confieso que he vivido (1974). Mientras que el primero llegó a manifestar que su estancia en la Unión Soviética en 1932 fue "como realizar un viaje del fondo de la noche al centro de la luz" (Alberti, 1997: 26), el segundo afirmó que para él Moscú se convirtió en "la magnífica capital del socialismo (...), la sede de tantos sueños realizados" (Neruda, 1984: 309). En el segundo grupo podrían situarse obras como Regreso de la URSS (Retour de l' URSS, 1936) ${ }^{12}$, de André Gide, dominada por la profunda sensación de desencanto que produjo en su autor, firme defensor de la utopía comunista soviética antes de su viaje, la constatación de que el régimen no estaba produciendo las transformaciones deseadas, de que sus dirigentes habían "dado gato por liebre al presentar como envidiable la situación de sus obreros" y de que, en definitiva", "la URSS no es (...) lo que había prometido ser" (Gide, 1982: 102).

\section{LA VISIÓN CRÍTICA E INDEPENDIENTE}

Frente a la entusiasta adhesión de unos y el crítico desengaño de otros, Zweig y Chaves Nogales escribieron sobre su estancia en la Unión Soviética de forma aséptica, limitándose a contar lo visto y oído en su viaje, sin hacer prácticamente ningún juicio de valor interpretativo. Ambos subrayaron su condición de testigos en sus textos. El escritor austriaco manifestó en las páginas preliminares de su autobiografía que consideraba "un deber dar fe de [su] vida, una vida tensa y dramáticamente llena de sorpresas" (Zweig, 2002: 14). Para evidenciar el valor testimonial de su obra $-y$, de forma específica, del fragmento que nos ocupa-, son constantes las descripciones detallistas y las alusiones a conversaciones concretas, llegando a incluir en ocasiones entrecomillados textuales, para dar así la sensación de que todo lo narrado es cierto y parte de la propia experiencia del autor. El deseo de ser objetivo, así como la falta de perspectiva global para valorar la situación rusa ${ }^{13}$, provocó que el autor se limitase a escribir una serie de artículos periodísticos y un epígrafe en sus memorias sobre su viaje, distinguiéndose así del resto de escritores que viajaban a la URSS, que "en seguida publicaban un libro de afirmación entusiasta o de negación exasperada” (Zweig, 2002: 426).

\footnotetext{
${ }^{12}$ Después de la primera edición, Gidé amplió y modificó algunas parte del texto, que se volvió a publicar como Retoques a mi "Regreso a la URSS" (Retouches à mon "Retour de l' URSS", 1937).

13 "El desconocimiento de la lengua me había impedido ponerme en contacto real con la gente del pueblo y, además, ¡qué pequeña era la parte de aquel imperio inabarcable que yo había visto en quince días!" (Zweig, 2002: 426).
} 
En el caso de Chaves Nogales, la autoridad de su testimonio y su correspondencia con la realidad viene dada, sobre todo, por su condición de periodista. Tal y como ha señalado Xavier Pericay (2010: 9), para el autor español "lo importante es que él había estado allí y que eso había que contarlo, (...) imperativo moral al que no puede ni debería sustraerse ningún periodista que se precie", y que en la obra se manifiesta en la insistencia con la que utiliza verbos de percepción sensorial. Y el propio Chaves Nogales (2012: 22) advertía en el prefacio de La vuelta a Europa en avión. Un pequeño burgués en la Rusia roja que "andar y contar" era su oficio.

Junto a esta intención de relatar lo acontecido en la Unión Soviética de forma veraz, sin prejuicios ideológicos de ningún tipo y otorgando más importancia a la descripción referencial de lo percibido que a cualquier tipo de reflexión política, los dos autores compartían un espíritu liberal y equidistante que les impedía adherirse a cualquier ideología de forma dogmática, algo que resultaba totalmente excepcional en un panorama como el de las décadas de 1920 y 1930, caracterizado por el extremismo político. Así, mientras que Zweig (2002: 414) -ejemplo, según Jordi Doce (2001) de "liberal que abomina del radicalismo y sus impulsos irracionales"- declaraba en su libro de memorias detestar en "lo más profundo de [su] ser todo lo político y dogmático", Chaves Nogales (2011: 4) siempre se definió a sí mismo como un "intelectual liberal". En el prólogo de $A$ sangre y fuego. Héroes, bestias y mártires de España (1937), una colección de relatos sobre la Guerra Civil en la que critica por igual los excesos violentos de uno y otro bando en la contienda, el literato y periodista afirmaba ser "antifascista y antirrevolucionario por temperamento" 14 y tener como "única y humilde verdad (...) un odio insuperable a la estupidez y la crueldad" (Chaves Nogales, 2012: 4). De ahí que, según Cintas Guillén (2001: 57), lo que se deduce de la lectura de su libro es que "Rusia no era el paraíso que algunos querían presentar, ni el infierno que deseaban otros" y "que los extremismos son malos, pero todavía peor es la ignorancia o la evasión de la realidad".

${ }^{14}$ Ese carácter liberal e independiente, contrario a cualquier manifestación dictatorial y totalitaria, es la que para algunos explica el desconocimiento generalizado que durante mucho tiempo ha habido de la figura de Chaves Nogales, así como su ausencia del canon de la literatura española: "Manuel Chaves es uno de los mejores escritores españoles del siglo XX, aunque perfectamente desconocido porque tuvo el capricho de no ser totalitario. De haberse humillado ante la burocracia estalinista ahora le estarían dedicando plazas. Y de haber galleado con los fascistas ya las tendría. Como era esa cosa tan rara en España, un demócrata con ideas propias, nadie le ha hecho el menor caso hasta que hace una década comenzó la recuperación” (Azúa, 2010). 


\section{REFLEXIONES DEL VIAJE}

Una de las razones que impulsó la atracción de los intelectuales, y de prácticamente toda la sociedad occidental, por lo que estaba ocurriendo en la Unión Soviética fue la convicción de que tras la revolución se estaba gestando una nueva sociedad, diferente a todas las conocidas y caracterizada por el fin de las divisiones clasistas y la aniquilación del sistema capitalista. La transformación de la Antigua Rusia no sólo implicaba el paso de una sociedad regida por unas estructuras casi feudalistas a una igualitaria, sino también la industrialización de un sistema de producción eminentemente agrario. Estos cambios, así como la teoría del "nuevo hombre soviético" que tan profusamente fue difundida desde el aparato propagandístico comunista ${ }^{15}$, no fueron ignorados por Zweig y Chaves Nogales. No en vano, el primero afirmaba al relatar las sensaciones previas a su viaje que, aunque "nadie sabía a ciencia cierta (...) qué pasaba en aquel país, (...) allí se gestaba algo completamente nuevo, algo que, de buen grado o por la fuerza, podría resultar determinante para la futura forma de nuestro mundo" (Zweig, 2002: 414). A pesar de que sus primeros contactos con el paisaje y la gente de la Unión Soviética le resultaron "curiosamente familiar[es]", sin "ninguna sensación de extrañeza" (2002: 416), por reconocer en aquello que veía lo mismo que años atrás había leído en las descripciones realistas de las novelas de Tolstoi, Dostoievski, Aksákov o Gorki, el escritor austriaco no dejó de asombrarse desde el inicio de su viaje de las diferencias existentes entre la sociedad soviética y las de los países europeos visitados por él hasta entonces:

Finalmente, llegamos a la estación fronteriza de Negorolie. Por encima de la vía se extendía una tira de tela roja como la sangre con una inscripción cuyas letras cirílicas yo era incapaz de leer. Me las descifraron: “iProletarios de todos los países, uníos!". Al pasar debajo de esa cinta de color rojo ardiente se entraba en el imperio del proletariado, la Unión Soviética, un nuevo mundo (Zweig, 2002: 416).

La llegada de Chaves Nogales al nuevo país no generó las mismas sensaciones de cambio y novedad que se produjeron en Zweig. Después de cruzar la frontera letona, de hecho, se sorprendió "volando sobre territorio ruso sin

\footnotetext{
${ }^{15}$ Grosso modo, la teoría del "nuevo hombre soviético" -que tuvo en Anton Makárenko a uno de sus principales representantes- propugnaba que la implantación del comunismo generaría la creación de un nuevo arquetipo humano saludable, altruista y culto que se comportara de acuerdo con los dogmas ideológicos que sustentaban el régimen.
} 
haber advertido ninguna solución de continuidad (...): todo exactamente igual" (Chaves Nogales, 2012: 115) ${ }^{16}$. Sin embargo, a medida que el avión fue avanzando, el periodista español fue advirtiendo las diferencias entre la Unión Soviética y el resto de países que había conocido en su viaje por Europa. Gracias a la perspectiva aérea de la que gozaba desde el avión, Chaves Nogales fue capaz de observar con un simple vistazo cómo "el campo ruso daba la impresión de estar absolutamente ocupado, tomado por (...) millones de campesinos" (2012: 115) diseminados de forma continua e irregular sin llegar a formar núcleos organizados de población. Más allá de estas diferencias, que evidenciaban que los procesos de urbanización que desde hacía décadas se habían consolidado en prácticamente toda Europa aún no se habían producido en la Unión Soviética -lo que revelaba la existencia de un sistema de producción diferente al de los países occidentales-, para Chaves Nogales la novedad de la Unión Soviética residía, fundamentalmente, en la tenacidad mostrada por el régimen bolchevique para intentar finiquitar las estructuras sociales, políticas y económicas de la Antigua Rusia:

Apenas se pone el pie en Moscú, se tiene súbitamente, de una vez, la sensación de que aquello ha sido arrasado por la revolución. Se ve en seguida que el bolchevismo ha arrancado de cuajo todo lo anterior, no ya las instituciones de gobierno, sino las raíces más hondas de la vida privada rusa, los fundamentos de la familia, los estímulos personales, todo. El bolchevismo ha querido hacer tabla rasa de todo lo anterior (2012: 122).

Lejos de cambiar por completo la fisonomía de Moscú, las tentativas de cambio del gobierno popular otorgaron a la capital un nuevo aspecto en el que se mezclaba el peso del pasado, la historia y la tradición con las novedades instauradas tras la revolución. Zweig y Chaves Nogales fueron conscientes del carácter abigarrado que semejante mezcolanza dio a la ciudad. Para el escritor austriaco, "la misma ciudad de Moscú era ya una disonancia" en la que "todo era viejo e indolente desde hacía demasiado tiempo, todo se había oxidado y, ahora, de golpe, quería volverse moderno, ultramoderno, supertécnico" (Zweig, 2002: 417-418). Quizá esa dualidad que el autor ob-

${ }^{16}$ La reflexión sobre la continuidad del paisaje detectada desde el cielo derivó en una crítica al sentimiento nacionalista: "Menos en eso de las fronteras, la tierra es exactamente igual a como se la habían imaginado los cartógrafos; a cierta altura volar es exactamente igual que pasar el dedo sobre el mapa. (...) Todo exactamente igual. Menos las fronteras, que se ve en seguida lo falsas que son, lo que tienen de convencional e inexistente" (Chaves Nogales, 2012: 114-115). El pensamiento de Chaves Nogales recuerda aquí irremediablemente al de Zweig (2002: 13), quien llegó a considerar al nacionalismo "la peor de todas las pestes (...), que envenena la flor de la cultura europea". 
servó en la capital soviética -sobre la que se extendió en sus reflexiones del viaje, en las que insistió en la idea de que la falta de homogeneidad afectaba también, a pesar del ideario comunista, a la distribución de la riqueza ${ }^{17}-$ explique que las sensaciones que, en líneas generales, le produjo el viaje fueran "como una corriente alterna entre frío y calor" en la que se combinaban "la aversión, el entusiasmo y la indignación" (Zweig, 2002: 417). Las impresiones de Zweig, que revelan la imparcialidad y el juicio crítico con los que observó la situación, coinciden con las de Chaves Nogales. También el escritor español fue consciente de cómo en Moscú se entablaba "una lucha a muerte entre la ciudad tradicional y el sentido revolucionario" (2012: 123):

El comunismo ha trastornado todos los valores humanos, está formando una nueva humanidad y, sin embargo, no ha podido cambiar en lo más mínimo este panorama de Moscú con su sentido feudal, sus viejas murallas, sus iglesias, sus monasterios, sus palacios y sus barrios silenciosos en los que perdura aquel encanto burgués de otro tiempo (Chaves Nogales, 2012: 124).

Uno de los principales generadores del cambio que se produjo en Rusia con la llegada al poder de los bolcheviques fue el proceso de industrialización, que transformó una estructura de producción basada casi exclusivamente en la agricultura con el fin de, además de conseguir el desarrollo económico y social, intentar resolver las contradicciones derivadas del hecho de haber puesto en práctica los postulados marxistas en un país "marcado por la pobreza, la ignorancia y el atraso, y donde el proletariado industrial, que Marx veía como el enterrador predestinado del capitalismo, solo era una minoría" (Hobsbawm, 2009: 65).

Stefan Zweig y Manuel Chaves Nogales no sólo fueron conscientes del modo en que la geografía urbana, especialmente la de Moscú y sus alrededores, estaba siendo modificada con la implantación de fábricas y pabellones industriales que contrastaban con el resto de construcciones de las ciudades, sino también del orgullo con el que la sociedad soviética contemplaba el progreso técnico y la evolución del país. Zweig (2002: 423) relata en su libro de memorias cómo los rusos "cuando enseñaban algo, por insignificante que

17 "Al lado de automóviles relucientes, unos (...) barbudos y zarrapastrosos fustigaban a sus magros jamelgos; la magnífica y zarista Gran Ópera (...) resplandecía con destellos pomposos ante un público proletario, y en los suburbios, cual anuncios sucios y abandonados, se levantaban unas casas viejas y destartaladas que tenían que apoyarse una contra otra para no desmoronarse" (Zweig, 2002: 41). 
fuera, les brillaban los ojos", mientras que Chaves Nogales (2012: 119) se refiere en La vuelta a Europa en avión. Un pequeño burgués en la Rusia roja al "entusiasmo soviético ante cualquier manifestación industrial" y a que "el fetichismo a la máquina es una de las características del bolchevismo". Para el periodista español, bajo ese sentimiento de orgullo subyacía la fe en el régimen y, en consecuencia, la certeza de que "el marxismo no podría implantarse hasta que la industria hubiese llegado a un grado de concentración del que Rusia dista mucho" (2012: 120).

Los dos autores coincidieron en calificar la admiración por todo lo relacionado con el desarrollo industrial como ingenuo, por cuanto revelaba un profundo desconocimiento de los equipamientos técnicos con los que se contaba en Occidente, tal y como expuso Zweig:

Cuántas veces se nos escapaba una sonrisa cuando nos enseñaban unas fábricas mediocres y esperaban que nos quedásemos maravillados como si nunca hubiéramos visto nada parecido en Europa o América: "eléctrica”, me dijo con orgullo un obrero, señalándome una máquina de coser y mirándome con la esperanza de que me deshiciera en elogios. Como el pueblo veía todos esos ingenios técnicos por vez primera, creía que los habían concebido e inventado la Revolución y los "padres" Lenin y Trotski (Zweig, 2012: 419).

En parecidos términos se expresó Chaves Nogales (2012: 119) -"no me maravillo demasiado de que haya allí unas chimeneas humeando y unos talleres donde se hacen tejidos"-, poniendo de manifiesto cómo la ignorancia sobre todo lo que acontecía fuera de su país llevaba a los soviéticos a ver como totalmente excepcional lo que en gran parte de Europa era normal. El desconocimiento sobre la situación internacional obedecía, fundamentalmente, a dos motivos. En primer lugar, a la intención del régimen bolchevique de infundir confianza y fe en el sistema en la ciudadanía al presentar como única y pionera en el mundo la experiencia de la industrialización, haciéndose así que todas las personas estuvieran "convencidas de que participaban en una gran causa que afectaba a toda la humanidad", provocando que "el viejo sentimiento de inferioridad respecto a Europa se [hubiese] convertido en un orgullo embriagador de llevar ventaja, de haberse adelantado a todo el mundo" (Zweig, 2002: 423). Y en segundo lugar, a censurar cualquier crítica procedente del exterior. Dada su condición de periodista, a Chaves Nogales le interesó sobremanera el modo en que el gobierno controlaba la información hasta hacer que "la incomunicación 
del pueblo ruso con el resto del mundo [fuera] absoluta":

De lo que pasa en el extranjero, el ciudadano de la URSS no tiene más noticias que las que le facilitan los boletines oficiales del Comisariado de Negocios Extranjeros. (...) Sólo aquellos acontecimientos a los que puede darse una interpretación revolucionaria ganan las columnas de la prensa. Yo he podido comprobar cómo personas que estaban al tanto del movimiento científico e intelectual de todos los países se hallaban absolutamente desorientadas en cuanto se refiere a la política internacional, hasta el punto de ignorar incluso la existencia de hechos de importancia capital para la marcha política del mundo (2012: 160).

Gracias a sus entrevistas con periodistas rusos, y a las traducciones a través de las que logró entrar en contacto con el contenido de los medios de comunicación, Chaves Nogales (2012: 157) llegó a la conclusión de que "en el régimen comunista, los periódicos no son más que escuderos de la Revolución" y "el periodista (...), un funcionario más de la maquinaria administrativa”. Según el autor español, semejante control de la información prohibía que en las páginas de los periódicos se mantuvieran "discusiones de carácter doctrinal" (159), pero, paradójicamente, no impedía que hubiera "una gran libertad para tratar de todas las cuestiones de la Administración según el criterio personal de sus redactores" (160).

El control de la información no fue el único que Chaves Nogales advirtió durante su viaje. El autor también se mostró crítico con la constante vigilancia a la que fue sometido por parte de la GPU, la policía política soviética ${ }^{18}$, cuyo poder tildó de "omnímodo en toda Rusia: (...) asume todos los poderes y disfruta de la más absoluta inviolabilidad” (2012: 152). El periodista y escritor español reconoció haber comprobado "la omnipresencia de los agentes de la GPU, [que] lo ven todo y lo saben todo" (151) de primera mano, puesto que confesó en su libro haber tenido la sensación de haber sido seguido y de que en todo momento se sabía hacia dónde se dirigía y con quién se entrevistaba. A pesar de reconocer la eficacia del cuerpo policial, al que llegó a calificar como "la mejor policía política del mundo", Chaves expresó la "angustia" que le generó la existencia "de unos individuos privilegiados que tienen en sus manos todos nuestros derechos y libertades" (151-152).

${ }^{18}$ Siglas de "Gosudarstvennoe Politicheskoe Upravlenie" (Directorio Político Unificado del Estado). Este cuerpo policial permaneció vigente hasta 1934, cuando pasó a formar parte del NKVD (Comisario del Pueblo para Asuntos Internos). Más tarde se integraría en la agencia de inteligencia KGB (Comité de Seguridad del Estado). 
En el caso de Zweig, la falta de libertad que provocaba la vigilancia constante de la policía política se veía incrementada por el hecho de ser una personalidad pública a la que las autoridades del país sometieron durante el tiempo que duró su estancia a una intensísima agenda de actividades destinadas, evidentemente, a mostrar los aspectos positivos del régimen y ocultar cualquier indicio de las irregularidades que lo rodeaban ${ }^{19}-$. En una carta escrita desde Moscú, el escritor reconocía a su mujer que "todo lo que le esperaba en aquellas dos semanas no le dejaba ni un segundo libre" (Matuschek, 2009: 241-252). En cualquier caso, un pasaje de sus memorias expone de forma muy clara cómo fue consciente del control al que fue sometido durante su viaje y de la imposibilidad que durante el tiempo que permaneció en la URSS tuvo de reunirse de forma aislada con ciudadanos soviéticos:

Sólo cuando cerré la puerta de mi habitación de hotel me quedé realmente solo, solo por primera vez después de doce días, en los que siempre había ido acompañado (...). Metí la mano en un bolsillo. [Encontré] una carta (...) escrita en francés (...) que alguien debía de haber deslizado hábilmente en mi bolsillo (...). Sin firma, (...) rebosaba irritación ante la creciente limitación de la libertad en los últimos años. "No crea todo lo que dicen -me escribía el desconocido-. No olvide que, a pesar de todas las cosas que le enseñan, dejan de enseñarle otras muchas. No olvide que las personas que hablan con usted, por lo general no le cuentan lo que les gustaría contarle, sino sólo aquello que se les permite decir. Nos vigilan a todos, incluido usted. Su intérprete informa de todo lo que se dice. Su teléfono está interceptado y controlados todos sus pasos". (...) Quemé la carta, siguiendo las instrucciones de su autor. "No se limite a romperla, pues recogerían los trozos de su papelera y la reconstruirían". Y por primera vez me puse a reflexionar sobre todo eso. ¿ No era un hecho real que, en medio de tanta cordialidad sincera, de toda aquella espléndida camaradería, no había tenido ni una sola ocasión de hablar con alguien en privado y con libertad? (Zweig, 2002: 425-426).

${ }^{19}$ El viaje de Zweig puede encuadrarse dentro de las "técnicas de hospitalidad" que, según Hollander (1987), desarrolló el gobierno soviético, a través de la Sociedad de Relaciones Culturales con el Extranjero, para controlar las impresiones extranjeras sobre la realidad del país a través de dos procedimientos: seleccionar las experiencias del viajero, permitiéndole percibir solo aquello que se deseaba que percibiera -lo que se hacía planificando el recorrido, programando eventos continuamente de forma que apenas tuviera libertad de movimientos y evitando encuentros no deseados- $y$ procurar que su estancia fuera lo más agradable posible. 
Más allá de estas reflexiones, y de la ironía con la que se refiere al "toque de ridículo" que provocaba, en su afán por lograr el ideal del "nuevo hombre soviético" el "esfuerzo puro y honrado de sacar al pueblo del analfabetismo de la noche a la mañana y llevarlo directamente a la comprensión de Beethoven y Vermeer" (Zweig, 2002: 419) ${ }^{20}$, apenas hay en las páginas de El mundo de ayer. Memorias de un europeo objeciones -ni tampoco adhesiones- al régimen bolchevique.

Frente al carácter eminentemente descriptivo del testimonio del autor austriaco, Chaves Nogales aporta una visión más poliédrica de la situación del país. Contribuyen a ello tanto la mayor duración de su viaje como la extensión y la complejidad formal de su texto, que le permiten incluir, dentro de la crónica general, "dramatizaciones de episodios reales" (Cintas Guillén, 2001: 58), entrevistas, y pequeños relatos basados en la observación de la realidad. Los contenidos, además, aparecen divididos por epígrafes, dando así cierta sensación de sistematización a su visión. Enemigo de los maniqueísmos y el pensamiento único, Chaves Nogales ofreció una interpretación de la realidad soviética en la que había lugar tanto para el elogio como para la invectiva.

Así, gracias a que su viaje no sólo tuvo como destino grandes ciudades, sino que también le permitió acercarse a zonas rurales y apartadas como las de la cordillera caucásica, el autor pudo admirar los esfuerzos de los bolcheviques por instruir y educar a la sociedad, e intentar llegar "hasta los rincones más apartados de Rusia, esos territorios vírgenes de toda civilización que el zarismo no supo sacar de la barbarie" (Chaves Nogales, 2012: 203). Chaves Nogales también elogió el hecho de que "nadie se [quedara] sin comer en Moscú" (133) y de que, en su lucha por la igualdad, el gobierno hubiera sido capaz de acabar con todas las bolsas de pobreza y marginación, excepto las de los huérfanos abandonados tras la guerra, convertidos en auténticos "niños salvajes" que, en palabras del autor, suponían "la gran vergüenza del régimen soviético" (148). No obstante, el hecho de que los ciudadanos tuvieran las necesidades básicas cubiertas no impidió que el autor rechazara la falta absoluta de "superficialidad" (133) de la vida en la Unión Soviética. Y es que tras la Revolución no sólo se eliminó todo vestigio de la burguesía zarista, sino que también se suprimieron de la

20 "En las escuelas, a los alumnos se les hacía pintar cosas absurdas y extravagantes y en los bancos de niñas de doce años se veían obras de Hegel y Sorel (a quien a la sazón ni yo mismo conocía); cocheros que aún no sabían leer del todo tenían en sus manos libros, simplemente porque eran eso: libros, y libros quería decir "instrucción", es decir, el honor y el deber del nuevo proletariado" (Zweig, 2002: 419). 
vida diaria todas las "pequeñas cosas sin importancia, (...) bagatelas, (...) naderías" (134) que forman parte de la vida del hombre civilizado y hacen que su rutina se distinga de la mecánica satisfacción de instintos primarios propia de los animales. De ahí que Chaves Nogales (2012: 135) -quien, a diferencia de Zweig, pudo conocer de primera mano el modo de vida de los soviéticos- otorgue el calificativo de "sórdida" a la vida bajo el régimen comunista.

Otro de los reproches del autor fue el referido a la violencia con la que el régimen había sido capaz de "eliminar a una clase social entera" (Chaves Nogales, 2012: 137) y criticó la situación en la que habían quedado en el país los popes -a quienes "se hace la vida imposible", obligándoles a "caer poco a poco en una especie de vagabundaje" (138)-, los comerciantes -convertidos en "los parias de la Rusia soviética" (140)- o cualquiera que tuviera cualquier relación con la antigua burguesía zarista. La capacidad represora del régimen también se demostraba en su capacidad para eliminar cualquier tipo de disidencia, como evidenciaba la persecución del gobierno hacia Trotsky -que, en el momento en que Chaves viajó a la Unión Soviética, permanecía desterrado en Kazajistán, acusado de violar la disciplina del Partido Comunista- y sus seguidores:

El trotskismo es el culto más perseguido hoy. Se ha llegado hasta el extremo de suprimir la cabeza de Trotsky en los grupos fotográficos en que aparecía Lenin rodeado de sus colaboradores; al cuerpo de Trotsky se le ha puesto, recortada, la cabeza de otro leader cualquiera. He visto, incluso, que los trotskistas más fervientes ni siquiera en lo más escondido de su hogar, ni en la cabecera de su cama, se atreven a tener la efigie de Trotsky, y a los que por devoción indestructible la conservan, para evitar el verse denunciados, la tapa durante el día con un paño blanco (Chaves Nogales, 2012: 205).

Asimismo, Chaves Nogales mostró su decepción ante la constatación de que, aunque la lucha por la igualdad fuera una de las señas de identidad del ideario comunista, las diferencias entre los técnicos -"hombres que saben que sus conocimientos son indispensables para el desenvolvimiento del régimen"- y el resto de la clase trabajadora estuvieran convirtiendo a los primeros en una especie de "nueva burguesía" y en un "elemento corruptor" (2012: 188). Tampoco favorecía la igualdad, en opinión del periodista, la "iconografía revolucionaria" (2012: 205) que poblaba el país y distinguía a la elite gubernamental del resto de la población. 


\section{CONCLUSIÓN: DOS MIRADAS DIFERENTES A LA REVOLUCIÓN}

Resulta complicado establecer similitudes entre los viajes que Zweig y Chaves Nogales llevaron a cabo en 1928. Podría llegar a decirse que el primero, que pasó poco más de dos semanas en el país, entre Leningrado, Tula y Moscú y con una agenda plagada de actividades y totalmente pautada por sus anfitriones, fue un turista, mientras que el segundo fue un auténtico viajero. Embarcado en la aventura de recorrer Europa en avioneta, Chaves realizó un periplo tan extenso que le llevó a recorrer 10.000 kilómetros dentro de la Unión Soviética. Con una libertad de movimientos mucho mayor que la del autor austriaco, y la consiguiente posibilidad de charlar con todo tipo de personas y visitar casi cualquier lugar, incluyendo exóticos destinos de los que dio cuenta con una mirada tan sorprendente y asombrada como la que los cronistas de Indias proyectaron sobre las tierras a las que viajaron en el siglo XVI, el periodista español vivió un crisol de situaciones heterogéneo y plural.

No obstante, ni las diferencias de sus viajes, ni las de las obras en las que se recogieron sus testimonios después de su publicación en los medios de comunicación, impiden detectar analogías en la mirada de ambos autores. En una época dominada por el dogmatismo y ante un tema en el que parecía imposible mantener una posición que no implicara la adhesión o el rechazo más absolutos, Stefan Zweig y Manuel Chaves Nogales fueron capaces de mantener el espíritu crítico, independiente y libre que siempre les caracterizó. Su visión no estuvo empañada ni por el prejuicio ideológico ni por la admiración que ambos demostraron sentir -y así lo hicieron constar en sus obras- por la cultura rusa. Los dos autores reconocieron estar presenciando un momento histórico, se congratularon por el hecho de poder ser testigos de primera mano del que era en aquellos momentos foco de atención universal y, sobre todo, coincidieron en su visión sobre la nueva realidad. A pesar de las diferencias de sus experiencias en la Unión Soviética, sus textos presentan una interpretación análoga en la que priman dos conclusiones. En primer lugar, tanto Chaves como Zweig fueron conscientes, tal y como señalaron continuamente, de las oceánicas dimensiones del cambio que la Revolución había generado, convirtiendo a la Antigua Rusia en un país totalmente diferente, con sus ventajas y sus inconvenientes, al resto del mundo. Y en segundo, ambos comprendieron cómo la falta de libertad era el gran problema del nuevo Estado, no sólo porque sufrieran los rigores de la censura y la vigilancia, sino sobre todo porque observaron la uniformidad y 
la ingenuidad de la sociedad, completamente incapaz de valorar en su justa medida lo que estaba sucediendo por su falta de perspectiva crítica y de referentes distintos a los ofrecidos desde el poder. Ahora bien, sus miradas, lejos de suponer una visión negativa de la realidad soviética, se limitaron a exponer, con la única imposición de ser fieles a lo vivido, las luces y las sombras del gran acontecimiento del momento. De ahí que los relatos de sus viajes no se parezcan a casi ninguno de los de sus coetáneos, pero, paradójicamente, supongan dos de las más valiosas visiones que desde la xenografía se han ofrecido de la Unión Soviética en los años inmediatamente posteriores a la revolución.

\section{REFERENCIAS}

Alberti, Rafael. (1997). La arboleda perdida II. Tercero y cuarto libros (19311987). Madrid: Alianza.

Azúa, Félix de. (2010). Manuel Chaves Nogales galopa de nuevo. Elboomeran(g) [on line]. Disponible en http://www.elboomeran.com/blog-post/1/8879/ felix-de-azua/manuel-chaves-nogales-galopa-de-nuevo/.

Castañar, Fulgencio. (1992). El compromiso en la novela de la II República. Madrid: Siglo XXI.

Caudet, Francisco. (1993). Las cenizas del Fénix. La cultura española en los años 30. Madrid: Ediciones de la Torre.

Chaves Nogales, Manuel. (2011). A sangre y fuego. Héroes, bestias y mártires de España. Barcelona: Libros del Asteroide. . (2012). La vuelta a Europa en avión. Un pequeño burgués en la Rusia roja. Barcelona: Libros del Asteroide.

Cintas Guillén, María Isabel. (2001). Un liberal ante la Revolución. Cuatro reportajes de Manuel Chaves Nogales. Sevilla: Universidad de Sevilla.

Coser, Lewis A. (1997). Men of ideas. A sociologist's view. New York: Simon \& Schuster.

Doce, Jordi. (2001). Las memorias de un europeo. Letras libres [on line]. Disponible en http://www.letraslibres.com/revista/letrillas/las-memorias-deun-europeo.

Dos Passos, John. (1984). Años inolvidables. Barcelona: Seix Barral.

Garfías, Pedro. (2001). Prosa reunida. Sevilla: Renacimiento.

Gide, André. (1982). Retorno de la URSS, seguido de Retoques a mi regreso de la URSS. Trad. Joan Casas. Barcelona: Muchnick.

Hobsbawm, Eric J. (2009). Historia del siglo XX. Barcelona: Crítica. 
Hollander, Paul. (1987). Los peregrinos politicos. Madrid: Playor.

Matuschek, Oliver. (2009). Las tres vidas de Stefan Zweig. Trad. Christina Sánchez. Barcelona: Papel de Liar.

Neruda, Pablo. (1984). Confieso que he vivido. Barcelona: Seix Barral.

Pericay, Xavier. (2010). El maestro Chaves Nogales que estaba allí. En Manuel Chaves Nogales, La agonía de Francia (pp. 9-14). Barcelona: Libros del Asteroide.

Sánchez Zapatero, Javier. (2008). Utopía y desengaño: análisis comparatista de los libros de viajes a la URSS. Estudios Humanisticos. Filología, 30, 289-284. Tood, Oliver. (2002). André Malraux. Una vida. Trad. Encarna Castejón. Barcelona: Tusquets.

Zweig, Stefan. (2002). El mundo de ayer. Memorias de un europeo. Trad. Joan Fontcuberta. Barcelona: Acantilado. 